This item was submitted to Loughborough's Research Repository by the author.

Items in Figshare are protected by copyright, with all rights reserved, unless otherwise indicated.

\title{
Horizontal deflection of single particle in a paramagnetic fluid
}

PLEASE CITE THE PUBLISHED VERSION

https://doi.org/10.1140/epje/i2014-14047-8

PUBLISHER

() EDP Sciences / Società Italiana di Fisica / Springer

\section{VERSION}

NA (Not Applicable or Unknown)

\section{PUBLISHER STATEMENT}

This work is made available according to the conditions of the Creative Commons Attribution-NonCommercialNoDerivatives 4.0 International (CC BY-NC-ND 4.0) licence. Full details of this licence are available at: https://creativecommons.org/licenses/by-nc-nd/4.0/

\section{LICENCE}

CC BY-NC-ND 4.0

\section{REPOSITORY RECORD}

Liu, Shi-Xiao, Xiang Yi, Mark C. Leaper, and Nicholas J. Miles. 2017. "Horizontal Deflection of Single Particle in a Paramagnetic Fluid". figshare. https://hdl.handle.net/2134/26845. 


\title{
Horizontal deflection of single particle in a paramagnetic fluid
}

\author{
S. Liu ${ }^{1 *}$ Xiang Yi ${ }^{2}$, M. Leaper ${ }^{3}$, N.J. Miles ${ }^{4}$
}

1. Process and Environmental Research Division, Faculty of Engineering, University of Nottingham, University Park, Nottingham, NG7 2RD, United Kingdom

2. Research Institute of Sun Yat-Sen University in Shenzhen, Hi-tech Industrial Park, Shenzhen, 518057, China

3. Chemical Engineering and Applied Chemistry, Aston University, Birmingham B4 7ET

4. Faculty of Science and Engineering, University of Nottingham Ningbo China, Taikang East Road, Ningbo, 315100, China

\section{Abstract}

This paper describes the horizontal deflection behaviour of a single particle in paramagnetic fluids under a high-gradient superconducting magnetic field. A glass box was designed to carry out experiments and test assumptions. It was found that the particles were deflected away from the magnet bore centre and particles with different density and susceptibility settled at a certain position on the container floor due to the combined forces of gravity and magneto-Archimedes as well as lateral buoyant (displacement) force. Matlab was chosen to simulate the movement of the particle in the magnetic fluid, the simulation results were in good accordance with experimental data. The results presented here, though is still very much in its infancy, which could potentially form the basis of a new approach to separating materials based on a combination of density and susceptibility.

Keywords: deflection; magnetic separation; paramagnetic fluid; susceptibility

\section{Introduction}

Magnetic phenomena have been known and exploited for many centuries [1]. Many kinds of magnetic separation techniques, such as beneficiation of iron ore, recovery of metal from waste material, attraction of very small ferro-magnetic particles onto steel filter wires (high gradient magnetic separation, HGMS), biomagnetic extraction of heavy metals and so on, have been developed and applied in industry. However, these techniques are restricted to 
treating ferromagnetic substances as the separation criteria are based on the repulsion/attraction towards the magnetic field [2-8].

Recently, the levitation of materials has become a topic of interest to a broad section of researchers [9]. There are two ways to levitate feeble magnetic substances, diamagnetic levitation and magneto-Archimedes levitation. The diamagnetic levitation of bismuth [10], the lifting of water [11] as well as the stable levitation of living frogs $[12,13]$ have been reported. The Magneto-Archimedes effect was first noted by Braunbeck in 1939[10]. Since then much work has been carried out and continued; Ikezoe et al. successfully levitated $\mathrm{KCl}$ and $\mathrm{NaCl}$ grains in pressurized oxygen gas[14] and also a $1 \mathrm{~cm}$ diameter water drop in the centre of a 10 Tesla magnet and levitated and separated Ti, C and $\mathrm{S}$ in $2.67 \mathrm{~mol} / \mathrm{l}$ solution of dysprosium nitrate[15]. This highlights the importance of the paramagnetic fluid (magneto-Archimedes agent) in providing the additional force to enable the particles to levitate. In addition, Hirota et al [16] in 2004 successfully used magneto-Archimedes separation to separate biological materials.

Comparing the two methods, the levitation of diamagnetic objects requires very large magnetic field-gradient products due to the small magnetic susceptibility of the diamagnetic materials, thus there are only a limited number of materials which could be diamagnetically levitated and only limited laboratories in the world could do this work [14].

In the presence of a background fluid, magneto-Arichimedes levitation applies the buoyancy principle to the levitation in a magnetic field, which could be modified as shown by the following equation [14]:

$\frac{\chi_{0}}{\mu_{0}} B \frac{d B}{d z}-\rho_{0} g-\frac{\chi_{f}}{\mu_{0}} B \frac{d B}{d z}+\rho_{f} g=0$

Where $\chi_{0}$ and $\rho_{0}$ are the magnetic susceptibility and density of the levitating object respectively and $\chi_{f}$ and $\rho_{f}$ are those of the background fluid. In diamagnetic levitation, the latter two terms on the left-hand side in Eq.(1) have been neglected. For the vertical direction magnet field gradient, the particle will endure four types of forces. Similar to wood in water, the particle in the media around it will receive a weight and buoyancy force provided by the media. Also the particle will be influenced by two further types of force, magnetic attraction and the magnetic levitation, which are related to the magnetic field strength. Here the 
levitation is known as the Magneto-Archimedes effect and the media called the MagnetoArchimedes agent [17-19].

Mir et al. [20] pioneered the use of ferrohydrostatic separators in 1973 by employing a kerosene-based ferrofluid to separate automobile scrap [20]. Considerable effort to develop this technology was subsequently expended in Japan and USA with a comprehensive review of the history of FHS in Japan and USA given by Fujita [21]. FHS technology has been used in industry to process gold and PGM concentrates as well as for diamond beneficiation but at a limited scale[22]. However, the fluids lack stability in contact with the atmosphere and the magnetic fluids are black in colour making the recovery and regeneration of the fluid a challenge, all of which must be addressed for large scale industrial implementation.

With the development of the design and synthesis of superconductivity material, it will be possible to generate high magnetic fields at low cost and weakly magnetic fluids could replace the current ferrofluids [1]. Over the past decade a considerable amount of research has been conducted at the University of Nottingham on the levitation of particles under high magnetic fields and gradients [23-25]. An interesting phenomenon was noticed during some of the levitation experiments, that the particles were repulsed to the wall of a container to form a ring around the centre of magnetic. This paper is based on this phenomenon and explores a horizontal direction magnetic deflection system, which potentially provides a new concept to separate particles with different density and magnetic susceptibility. A model has been set up to simulate the phenomenon of deflection, which shows good accordance with the experimental results.

\section{Experimental procedure}

\subsection{Materials}

Manganese (II) chloride aqueous solution was used as the magnetic fluid during the experiments. A $4 \mathrm{~mol} / \mathrm{l}$ solution was prepared by dissolving analytically pure $\mathrm{MnCl}_{2}$ in distilled water with the density and susceptibility of the resultant solution being $1395 \mathrm{~kg} \mathrm{~m}^{-3}$ and $6.6 \times 10^{-4} \mathrm{~m}^{3} \cdot \mathrm{kg}^{-1}$, respectively, which was used in all the following experiments where it was required. A range of well defined particulate materials were used including pyrite and glass 
spheres as well as a real mineral ore (copper sulphide ore). The physical properties of the pyrite and glass spheres used in the experiments are listed in Table. 1.

\subsection{Superconducting Magnet}

The experiments were performed using an Oxford Instruments Minimum Condensed Volume (MCV) superconducting magnet, which had a $5 \mathrm{~cm}$ diameter open bore with the maximum magnet central field being about 17 Tesla in the magnet bore, and the maximum $\mathrm{BdB} / \mathrm{dZ}$ field gradient about $\pm 1470 \mathrm{~T}^{2} \mathrm{~m}^{-1}$. The picture of the superconducting magnet is shown in Fig. 1a. The maximum field strength position is about $19 \mathrm{~cm}$ down into the bore from the top plate of the superconducting magnet. The magnet field strength from the top plate of the superconducting magnet rig is shown in Fig. $\mathbf{1 b}$.

\subsection{Design of glass box}

As observed in the trial tests, the particles levitated in the Magneto-Archimedes fluid were repulsed to the wall of a container in the superconducting magnet field centre area.

In order to explore this interesting behaviour, a rectangular glass box was made with dimensions, $145 \times 195 \times 25 \mathrm{~mm}$. The box was placed on top of the magnet as shown in Fig. 2 with one of the end faces being positioned over the centre of the magnet bore. This was the point where the particles were fed or introduced in the fluid.

\subsection{Data collection}

When a single particle was placed into the liquid at the end of the box close to the magnet bore centre as shown in Fig. 2, a video camera was used to record the movement of the particle. The individual frame with 0.1 second interval was analysed to extract the path of particle during deflection.

\subsection{Numerical simulation details}

\subsubsection{Equilibrium of a particle in a magneto-Archimedes solution}

$M A T L A B$ is a numerical computing environment and fourth generation programming language, recently many researchers used this kind of software to develop the numerical modelling in engineering areas[26-29]. Numerical simulation of particle behaviour in a 
magnetic field was carried out to explore the deflection phenomena during the single particle experiments using Matlab software. To find a suitable model to simulate the process, the first step was to calculate the equilibrium of a particle in a magneto-Archimedes solution. To analyze the detailed forces acted on the particle, the forces were extracted to horizontal direction force $F_{r}$ and vertical direction force $F_{z}$. From the equation of magnetic energy[13] ,

$$
U_{m a g}=k \quad \frac{B^{2}}{2 \mu_{0}}
$$

The equation of $F_{r}$ and $F_{z}$ can be achieved as below[30].

$$
\begin{aligned}
& F_{z}=\frac{d U}{d z}=\frac{k V}{2 \mu_{0}} * \frac{d\left(B^{2}\right)}{d z}=\frac{k V B}{\mu_{0}} * \frac{d B}{d z} \\
& F_{r}=\frac{k V B}{\mu_{0}} * \frac{d B}{d r}
\end{aligned}
$$

The above vertical force is just the magnetic vertical direction force. But actually the particle in the magneto-Archimedes fluid should stand the buoyancy force provided by the solution. Combing the gravity and buoyancy, the vertical direction force in total could be summarised as below [24]:

$$
F_{z}=\left(k_{p}-k_{l}\right) V B \frac{d B}{d z} * \frac{1}{\mu_{0}}-\left(\rho_{P}-\rho_{l}\right) V g
$$

The horizontal direction force also could be summarised as the following formula considering the solution effect.

$$
F_{r}=\left(k_{p}-k_{l}\right) V B \frac{d B}{d r} * \frac{1}{\mu_{0}}
$$

The total magnetic field strength of every position is the combination of horizontal and vertical direction magnetic field strength as shown below. Where $Z$ means the vertical direction and $r$ means the horizontal direction.

$$
B=\sqrt{B_{z}^{2}+B_{r}^{2}}
$$

In the above equation, the total magnetic field strength $B$ and vertical direction magnetic field gradient $\frac{d B}{d z}$, horizontal direction magnetic field gradient $\frac{d B}{d r}$ can be measured on site. 
Based on the measured magnetic field strength data, the force of the particles could be calculated.

\subsubsection{Horizontal deflection simulation}

As to the deflection paths of the particle in $4 \mathrm{M} \mathrm{MnCl}_{2}$ solution during the simulation, the velocity and displacement of the particle can be modelled according to the following fundamental formulas.

The relevance between the force and velocity acceleration can be shown as below

$$
f=m a
$$

The relationship between the original velocity and the instantaneous velocity could be described as

$$
\begin{aligned}
& v_{t}=v_{o}+a t \\
& v_{t}^{2}-v_{o}^{2}=2 a S
\end{aligned}
$$

Combining with the above formulas, the displacement of the particle can be summarised as following.

$$
S=v_{0} t+\frac{f t^{2}}{2 \rho V}
$$

According to the fundamental formulas on the force and velocity listed above, the track of particle can be simulated by computer based on the calculated forces in the above section.

\section{Results and discussion}

\subsection{Single particle experiment}

As manganese chloride solution is paramagnetic, it will be attracted close to the magnetic field centre, which leads to the slight distortion of the liquid surface [13], this had been observed during the experiments as well.

Fig. 3 ( $a$ and b) presents the horizontal deflection of glass particles in a $4 \mathrm{M} \mathrm{MnCl}_{2}$ solution under different magnetic fields from 9.5 $\mathrm{T}$ to $16.5 \mathrm{~T}$, which is a typical phenomenon of particle horizontal deflection in a magnetic fluid. The glass particle was dropped into the container at the point above the angle position. The $\mathrm{X}$ axis represents the length of the glass box, which is about 195mm and the $Y$ axis represents the height of the glass box, which is about $145 \mathrm{~mm}$. The right side of the figure was one side of the glass box which was close to the magnet bore 
centre. The left side of the figure is the side of the glass box which is far away from the bore centre.

It can be seen from Fig. 3 ( $a$ and $b$ ) that the deflection behaviour and track of a particle at different magnetic field strengths was different. The particle was deflected more under a stronger field and took more time to settle to the bottom of the container due to the stronger buoyancy force competing with gravity.

The deflection behaviour of a glass particle with different sizes (diameters) is shown in Fig. 4a, It would seem that a glass particle with a diameter of $0.7 \mathrm{~mm}$ behaved similarly to that of a $1 \mathrm{~mm}$ diameter one, which indicated that the size of particle did not have an obvious effect on the horizontal deflection. This supports our assumption as the variation of particle size would not change the vertical and horizontal forces' balance acted on the particle, thus the influence of particle size on the particle deflection should be negligible.

Several experiments were conducted to explore the deflection of glass and pyrite under similar conditions, which is shown in Fig. $\mathbf{4 b}$. It was clear that the pyrite and glass particles were separated as the particles settled down at different positions on the container floor due to the balance between the buoyancy force and gravity.

\subsection{Deflection of particles in the cylinder}

According to the previous results on the deflection of a single particle in a paramagnetic fluid, it could be presumed that the particles group will tend to show the same deflection behaviour when they were put into the same magnetic system. A cylinder shown in Fig. 5a was used to carry out the experiments (the particles were dropped from the top of the magnet bore centre), the result is shown in Fig. $\mathbf{5 b}$. Two clear rings were formed in the cylinder due to the deflection movement of particles, the inner ring with a dark colour of pyrite particles and an outer ring of sand particles. The sand particles were deflected furtheraway from the centre of the cylinder than the pyrite particles, which was due to the force balance between gravity and levitation as well as the unbalanced horizontal force raised by the distribution of the magnetic field.

\subsection{Simulation results}




\subsubsection{Forces acted on particles in magnetic field}

Based on the equations in section2.5.1, Matlab was chosen to measure the total forces acting on the particles in magnetic field. The total forces acting on glass particle in $4 \mathrm{M} \mathrm{MnCl}_{2}$ solution under the magnetic field of 16.5T was shown in Fig. 6. Different colour in the graph represents different force acting on particles. It can be seen that the forces were smaller as the height increased ( $Z$ vertical distance from the magnet bore centre) and the radial distance increased( $r$ : the radial distance from the magnet bore centre).

\subsubsection{Single particle movement in magnetic field}

It was indicated from the experiments aforementioned that under different magnetic field, the particles were deflected in different paths. The modelling result of this was shown in Fig. 7. It is clear again that the glass particle $(\mathrm{d}=1 \mathrm{~mm}$, Fig. 7a) had different deflection path under different magnetic field strength. The stronger magnetic field strength, the glass particle was deflected more and settled at positions away from the bore centre. The different paths of glass particle and pyrite particle were modelled and the results are shown as Fig. $\mathbf{7 b}$, which indicate that the pyrite and glass particle were deflected at different paths and settled at certain positions due to the difference of density and magnetic susceptibility.

The effect of particle size on the horizontal deflection had been modelled as well, the results are shown in Fig. 7c and Fig. 7d. It could be indicated that particle size had negligible effect on the horizontal deflection, at least for the size ranged examined in these modelling work $(+0.7-5 \mathrm{~mm})$. Comparing the modelling work(Fig. 7) with the experimental results(Fig. 3 and Fig. 4), it is clear that the simulation method is reliable and almost got the same trend of particle movement in magnetic field as that in experiments. Thus, presumably, this simulation method could be potentially developed and used to predict the behaviour of particles in more complicated system

\subsection{Discussion}

Separation in magnetic fluids is a sink-and-float technique, which exploits differences in the densities and susceptibilities of materials to be separated. In this technique, a magnetic fluid, placed in a non-homogenous magnetic field, exhibits an apparent density difference from its natural density[8]. This apparent density can be controlled through a wide range of 
values[13]. The vertical balance of forces(levitation and gravity) on particles could be described by Fig. 8a when the particles are sitting in the centre of magnetic field[5].

However, when it comes to the horizontal deflection, if the particles deviate from the centre of magnetic field (Fig. 8b), due to the uneven distribution of magnetic field in the horizontal direction characterized by high density in the middle of magnetic poles and low density at the outside of magnetic poles, two kinds of forces acted on particle: magnetic force ( $f_{x}$, attracting particle toward the centre of magnetic poles) and magnetic repulsion force $\left(f_{R}\right.$, repulsing particle to the outside magnetic poles). Usually $f_{R}$ is stronger than $f_{x}$, which is the main factor leading to the particles' horizontal deflection.

As there are still vertical balance between buoyancy and gravity, the trajectory of particles will be a curve instead of straight line.

Experimental results were in good accordance with those of simulation, both of them indicated the horizontal deflection of particles among magnetic fluid under strong magnetic field, which could be potentially developed to separate particles as per the differences in density and/or susceptibility.

\section{Conclusions}

The concept of separation of non-magnetic particles suspended in a magnetic fluid is based on the Magneto-Archimedes principle whereby, in addition to the conventional force of gravity acting on the fluid, also a magnetically induced force acts on the fluid. This additional magnetic pull creates a magnetically induced buoyancy force on a particle immersed in the fluid. Based on this, a glass box and cylinder were designed to investigate the movement of particles in magnetic fluid. It was found that particles were repulsed to the inner wall of a cylinder to form a ring. Pyrite and glass particles were deflected and settled at certain positions in a specially designed container due to differences in their densities and magnetic susceptibilities. The density and susceptibility of particles, as well as the magnetic field strength were found to be the major factors influencing the movement of particles. Particle size (diameter) seemed to have little influence on the results, at least for the size range examined in these experiments $(+0.106-3 \mathrm{~mm})$. Similar results were obtained for experiments 
and mathematical simulation. It is appreciated that extending this range, particularly to the finer sizes, would increase the influence of other types of forces, eg, hydrodynamic forces, on the separation behaviour. The horizontal deflection behaviour of the particles provides a new concept for the potential separation of minerals and materials. These are very early results and considerable more work is required to understand the basic system, not least, the behaviour of fluids that could potentially be used as magneto-Archimedes agents. This work is continuing in collaboration with physicists and is currently exploring a broader range of particle types and sizes as well as potential hydrodynamic forces.

\section{Acknowledgements}

This work was funded as part of the UK Engineering and Physical Sciences Research

Council Basic Technology Programme: Magnetic Levitation Technology for Mineral Separation, Nanomaterials, and Biosystems for Space Exploration (GR/S83005/01)

\section{Reference:}

[1] J. Svoboda, Magnetic techniques for the treatment of materials, Kluver Academic Publishers, 2004.

[2] K. Yokoyama, T. Oka, H. Okada, Y. Fujine, A. Chiba K. Noto, Solid-Liquid Magnetic Separation Using Bulk Superconducting Magnets, ITAS. 13(2003)1592-1595.

[3] R.D. Doctor and C.D. Livengood, http://www.p2pays.org/ref/14/13875.pdf, 228-235.

[4] H. Okada, H. Okuyama, M. Uda and N. Hirota, Removal of Aerosol by Magnetic Separation, ITAS. 16(2006)1084-1087.

[5]I. Ihara, K. Kanamura, E. Shimada and T. Watanabe, High Gradient Magnetic Separation Combined With Electrocoagulation and Electrochemical Oxidation for the Treatment of Landfill Leachate, ITAS.14(2004)1558-1560.

[6] D. Ito, K. Miura, T. Ichimura, I. Ihara and T. Watanabe, Removal of As, Cd, $\mathrm{Hg}$ and $\mathrm{Pb}$ Ions From Solution by adsorption with Bacterially-Produced Magnetic Iron Sulfide Particles Using High Gradient Magnetic Separation, ITAS. 14(2004)1551-1553. 
[7] H. Okada, Y. Kudo, H. Nakazawa, A. Chiba, K. Mitsuhashi, T. Ohara, and W. Hitoshi, Removal System of Arsenic From Geothermal Water by High Gradient Magnetic SeparationHGMS Reciprocal Filter, ITAS. 14(2004)1576-1579.

[8] T. Hartikainen, J. Nikkanen and R. Mikkonen, Magnetic Separation of Industrial Waste Waters as an Environmental Application of Superconductivity, ITAS. 15(2005)2336-2339.

[9] M. Mothokawa, M. Hamai, T. Sato, I. Mogi, S. Awaji, K. Watanabe, N. Kitamura, M. Makihara, levitation experiments in Tohoku University, Physical B, 294-295(2001)729-735.

[10] W. Braunbeck, Magnetic levitation of graphite, Z. Physics, 112(1939)735.

[11] E. Baeugnon and R. Tournier, Levitation of organic materials, Nature, 349(1991)470.

[12] A.K. Geim, M.D. Simon, M.I. Boamfa and L.O. Heflinger, Magnet Levitation at Your Fingertips, Nature, 400(1999)323.

[13] M.V. Berry and A.K. Geim, Of flying frogs and levitrons, Eur. J. Phys. 18(1997)307.

[14] Y. Ikezoe, T. Kaihatsu, S. Sakae, H. Uetake, N. Hirota, K. Kitazawa, Separation of feeble magnetic particles with magneto-Archimedes levita, Energy Convers. Manage. 43(2002)417425.

[15] P.A. Dunne, J. Hilton, J.M.D. Coey, Levitation in paramagnetic liquids, J. Magn. Magn. Mater. 316(2007)273-276.

[16] N. Hirota, M. Kurashige, M. Iwasaka, M. Ikehata, H. Uetake, T. Takayama, H. Nakamura, Y. Ikezoe, S. Ueno, and K. Kitazawa, Magneto-Archimedes separation and its application to the separation of biological materials, Phys. B. 346-347(2004)267-271.

[17] R.E. Rosenweig, R.E., Buoyancy and stable levitation of a magnetic body immersed in a magnetizable fluid, Nature, 210(1966)613-614.

[18] R.E. Rosenweig, Fluidmagnetic Buoyancy, AIAA Jour. 4 (1966)1751-1758.

[19] R.E. Rosenweig, Ferrohydrodynamics, Dover publications, New York. ISBN 0-48667834-2,1997.

[20] L. Mir, C. Simard and S.D. Grana: in: Proc. $3^{\text {rd }}$ Urban Technol. Conf. Tech. Display, Boston(USA), AIAA Paper no. 73-959, 1973.

[21] T. Fujita: Separation of nonmagnetic particles with magnetic fluid. In:Magnetic Fluids and Applications Handbook(B.Berkovski and V.Bashtovoy, Editors, Begell House, Inc., New York, 1996. 
[22] J. Svoboda, Densimetric Separation of Coal Using Magnetic Fluids, Physi. Sepa. Sci. \& Eng. 13(2004)127-139.

[23] A.T. Catherall, L. Eaves, P.J. King and S. Booth, Floating gold in cryogenic oxygen, Nature. 422(2003)579.

[24] A.T. Catherall, P. Lopez-Alcaraz, K.A. Benedict, P.J. King and L. Eaves, Cryogenically enhanced magneto-Archimedes levitation, New Journal of Physics, 7(2005)118-127.

[25] P. Lopez-Alcaraz, A.T. Catherall, R.J.A. Hill, M.C. Leaper, M. Swift and P.J. King, Magneto-vibratory separation of glass and bronze granular mixtures immersed in a paramagnetic liquid, The European Physical Journal E. 24(2007)145-156.

[26] Y.J. Choi, K.L. McCarthy and M.J. McCarthy, A MATLAB graphical user interface program for tomographic viscometer data processing, COMPUT ELECTRON AGR. 47(2005)59-67.

[27] L. Pangione and J.B. Lister, Matlab modeling of ITER CODAC, Fusion Eng. Des. 83(2008)545-551.

[28] C.L. Lim, N.B. Jones, S.K. Spurgeon and J.J.A. Scott, Modelling of knee joint muscles during the swing phase of gait-a forward dynamics approach using MATLAB/Simulink, Simulation Modelling Practice and Theory, Simul. Modell. Pract. Theory, 11(2003)91-107. [29] Q.X. Feng, Q. Feng and K. Takeshi, Availability of MCNP \& MATLAB for reconstructing the water-vapor two-phase flow pattern in neutron radiography, Nucl. Sci. Tech. 19(2008)282289.

[30] M.D Simon and A.K. Geim, Diamagnetic levitation: Flying frogs and floating magnets, J. Appl. Phys. 87(2000)6200-6204. 


\begin{tabular}{|c|c|c|}
\hline$a$ & general acceleration of velocity & $\left(\mathrm{m} \cdot \mathrm{s}^{-2}\right)$ \\
\hline$B$ & the magnetic induction field strength & $(T)$ \\
\hline$B_{r}$ & horizontal direction magnetic field strength & $(\mathrm{T})$ \\
\hline$B_{z}$ & vertical direction magnetic field strength & $(\mathrm{T})$ \\
\hline$B^{\prime}$ & vertical direction magnetic field gradient & $\left(T \cdot m^{-1}\right)$ \\
\hline$C_{\text {salt }}$ & mass percentage of salt in the total mass & $(-)$ \\
\hline$F$ & magnetic force per unit mass & $\left(\mathrm{N} . \mathrm{kg}^{-1}\right)$ \\
\hline$F_{m}$ & the magnetic attractive force & $(\mathrm{N})$ \\
\hline$F_{r}$ & horizontal direction force & $(\mathrm{N})$ \\
\hline$F_{z}$ & vertical direction force & $(\mathrm{N})$ \\
\hline$F_{z}{ }^{\prime}$ & per unit mass of horizontal magnetic force & $\left(\mathrm{N} . \mathrm{kg}^{-1}\right)$ \\
\hline$f$ & general Force & $(\mathrm{N})$ \\
\hline$g$ & the acceleration of gravity & $\left(m \cdot s^{-2}\right)$ \\
\hline$H$ & the magnetic field intensity & $\left(A \cdot m^{-1}\right)$ \\
\hline$H_{a}$ & the applied field intensity & $\left(A \cdot m^{-1}\right)$ \\
\hline$k$ & volume magnetic susceptibility & $(-)$ \\
\hline$k_{1}\left(\right.$ or $\left.k_{p}\right)$ & mass susceptibility of the levitating substances & $(-)$ \\
\hline$k_{2}\left(\right.$ or $\left.k_{l}\right)$ & mass susceptibility of the medium gas (or liquid) & $(-)$ \\
\hline$M$ & induced magnetization of the particle & $\left(A \cdot m^{-1}\right)$ \\
\hline$M_{m}$ & molar mass & $\left(\mathrm{kg} \cdot \mathrm{mol}^{-1}\right)$ \\
\hline$m$ & the mass of the particle & $(\mathrm{kg})$ \\
\hline$S$ & displacement & $(\mathrm{m})$ \\
\hline$t$ & time & $(\mathrm{s})$ \\
\hline$U_{\text {mag }}$ & magnetic energy & $\left(m^{4} T^{2} \cdot H^{-1}\right)$ \\
\hline$V$ & particle volume & $\left(\mathrm{m}^{3}\right)$ \\
\hline$V_{m}$ & molar volume of the substance & $\left(\mathrm{m}^{3} \cdot \mathrm{mol}^{-1}\right)$ \\
\hline$v_{t}$ & velocity after time $t$ & $\left(\mathrm{~m} \cdot \mathrm{s}^{-1}\right)$ \\
\hline$v_{0}$ & velocity at time is zero & $\left(m \cdot s^{-1}\right)$ \\
\hline$W$ & per unit volume of magnetic energy & $\left(\mathrm{mT}^{2} \cdot \mathrm{H}^{-1}\right)$ \\
\hline$X$ & the specific magnetic susceptibility & $\left(\mathrm{kg}^{-1}\right)$ \\
\hline$X_{m}$ & molar susceptibility & $\left(\mathrm{m}^{3} \cdot \mathrm{mol}^{-1}\right)$ \\
\hline$x$ & mass magnetic susceptibility & $\left(\mathrm{m}^{3} \cdot \mathrm{kg}^{-1}\right)$ \\
\hline$\mu_{0}$ & the permeability of free space & $\left(\mathrm{H} \cdot \mathrm{m}^{-1}\right)$ \\
\hline$\rho$ & mass density & $\left(\mathrm{kg} \cdot \mathrm{m}^{-3}\right)$ \\
\hline$\rho_{1}$ & the density of the levitating substances & $\left(\mathrm{kg} \cdot \mathrm{m}^{-3}\right)$ \\
\hline$\rho_{a}$ & the apparent density of liquid & $\left(\mathrm{kg} \cdot \mathrm{m}^{-3}\right)$ \\
\hline$\rho_{2}\left(\operatorname{or} \rho_{l}\right)$ & density of medium gas (or liquid) around it & $\left(\mathrm{kg} \cdot \mathrm{m}^{-3}\right)$ \\
\hline
\end{tabular}




$\begin{array}{lll}\rho_{L} & \text { actual density of liquid } & \left(\mathrm{kg} \cdot \mathrm{m}^{-3}\right) \\ \frac{d H}{d X} & \text { the magnetic field gradient } & \left(\mathrm{A} \cdot \mathrm{m}^{-2}\right) \\ \frac{d B}{d z} & \text { vertical direction magnetic field gradient } & \left(\mathrm{T} . \mathrm{m}^{-1}\right) \\ \frac{d B}{d r} & \text { horizontal direction magnetic field gradient } & \left(\mathrm{T} . \mathrm{m}^{-1}\right)\end{array}$

Table. 1 Physical properties of pyrite and glass spheres

\begin{tabular}{ccccc}
\hline Materials & Particle size & Density $\left(\mathrm{kg} \mathrm{m}^{-3}\right)$ & $k_{\mathrm{p}} \times 10^{-6}$ & $X_{\mathrm{p}} \times 10^{-9} \mathrm{~m}^{3} \mathrm{~kg}^{-1}$ \\
\hline Pyrite & $+0.7-1.2 \mathrm{~mm}$ & 5000 & 338 & 67.5 \\
Glass spheres & $0.7 \& 1.0 \mathrm{~mm}$ & 2472 & $(-)$ & $(-)$ \\
\hline
\end{tabular}

\section{Horizontal deflection of single particle in a paramagnetic fluid}

\section{List of Figures}

Fig. $1 \mathrm{MCV}$ magnet system used in experiments

Fig. 2 Experimental setup with glass container

Fig. 3 The deflection of glass particle under different magnetic field

Fig. 4 The deflection of glass and pyrite particle at 16.5T

Fig. 5 The deflection of sand and pyrite in cylinder(16.5T, $\left.4 \mathrm{M} \mathrm{MnCl}_{2},+0.15-0.2 \mathrm{~mm}\right)$

Fig. 6 Forces acted on glass particle $(d=1 \mathrm{~mm})$ in magnetic field $\left(B_{c}=16.5 \mathrm{~T}\right)$

Fig. 7 Simulation results of particle deflection in magnetic field

Fig. 8 Forces acted on particles in magnetic field 
All the colour figures are intended for colour reproduction on the web and black-and-white in print. 


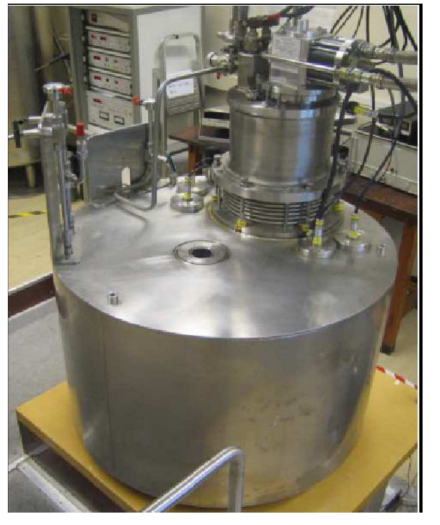

a. MCV magnet system

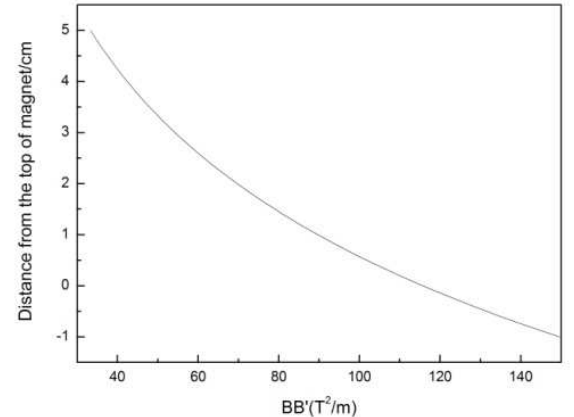

b. BB' Vs distance from the top of magnet

Fig. 1 MCV magnet system used in experiments

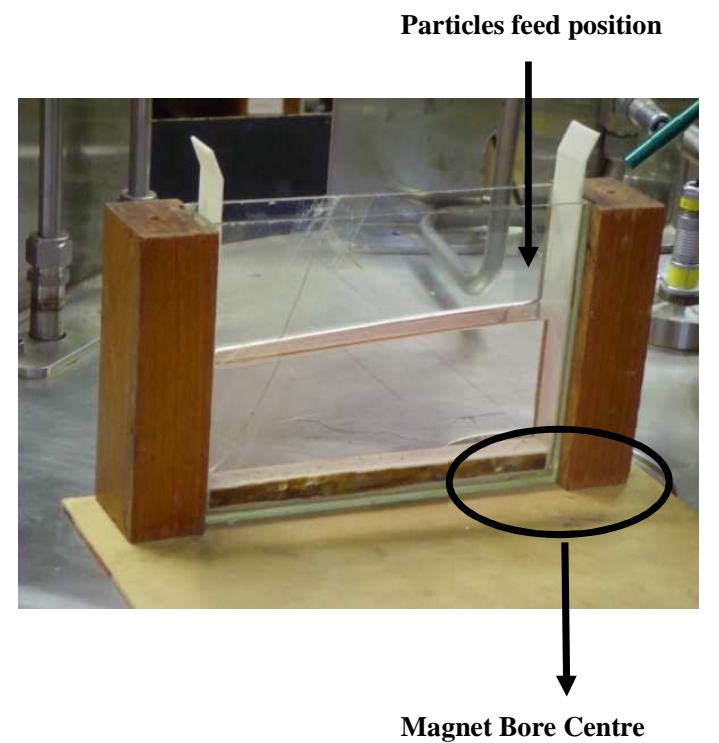

Fig. 2 Experimental setup with glass container 


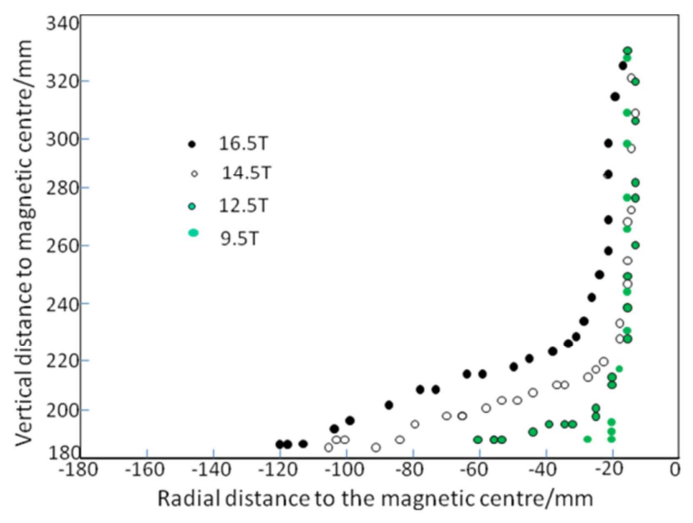

a. glass particle with $\mathrm{d}=1 \mathrm{~mm}$

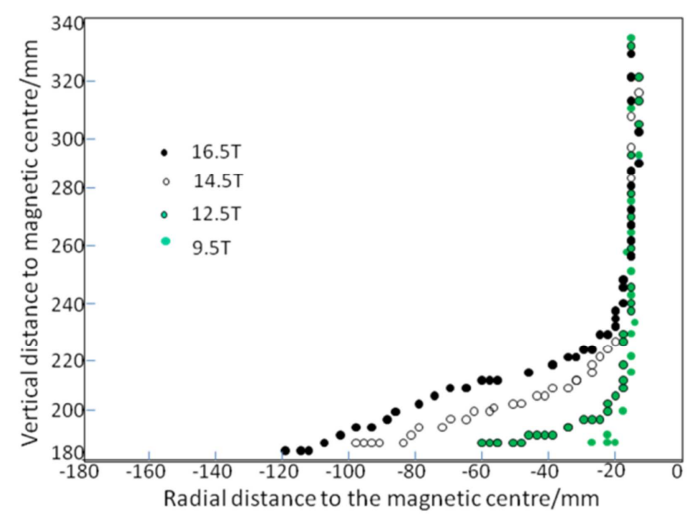

b. glass particle with $\mathrm{d}=0.7 \mathrm{~mm}$

Fig. 3 The deflection of glass particle under different magnetic field

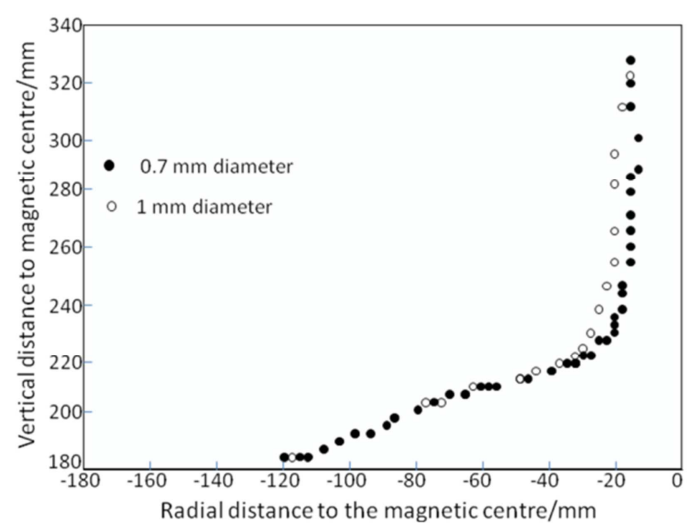

a. glass particle with $\mathrm{d}=1 \mathrm{~mm}$

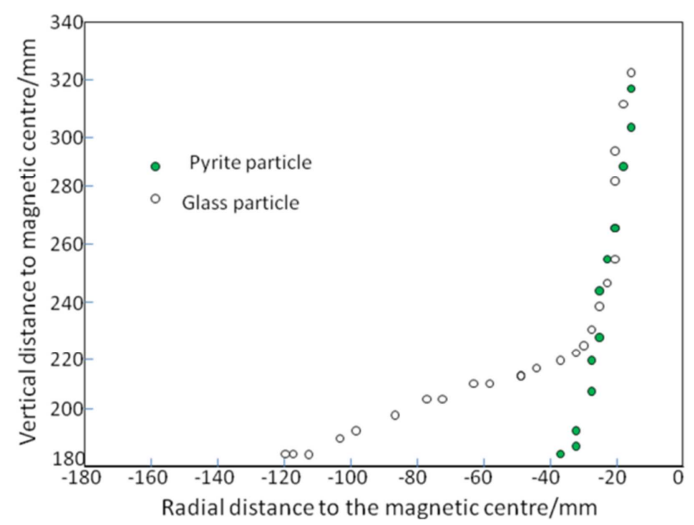

b. glass $(\mathrm{d}=0.7 \mathrm{~mm})$, pyrite $(+0.7-1.2 \mathrm{~mm})$

Fig. 4 The deflection of glass and pyrite particle at 16.5T

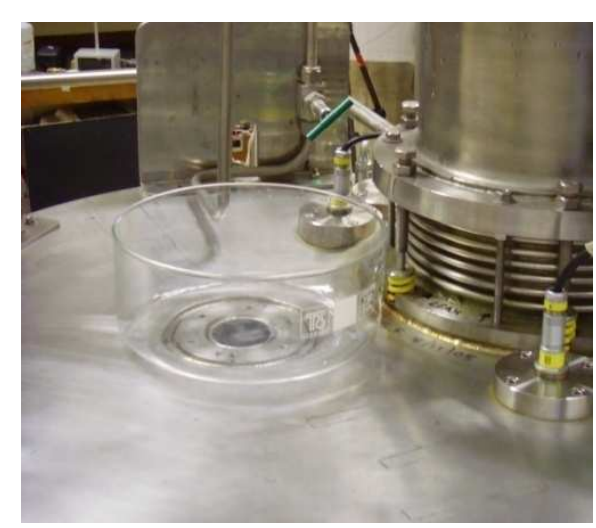

a. Experimental setup

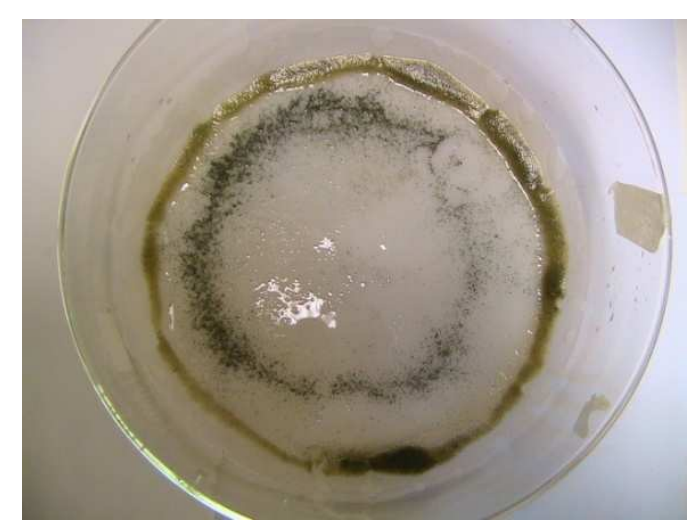

b. Two rings formed in the cylinder

Fig. 5 The deflection of sand and pyrite in cylinder(16.5T, $\left.4 \mathrm{M} \mathrm{MnCl}_{2},+0.15-0.2 \mathrm{~mm}\right)$ 


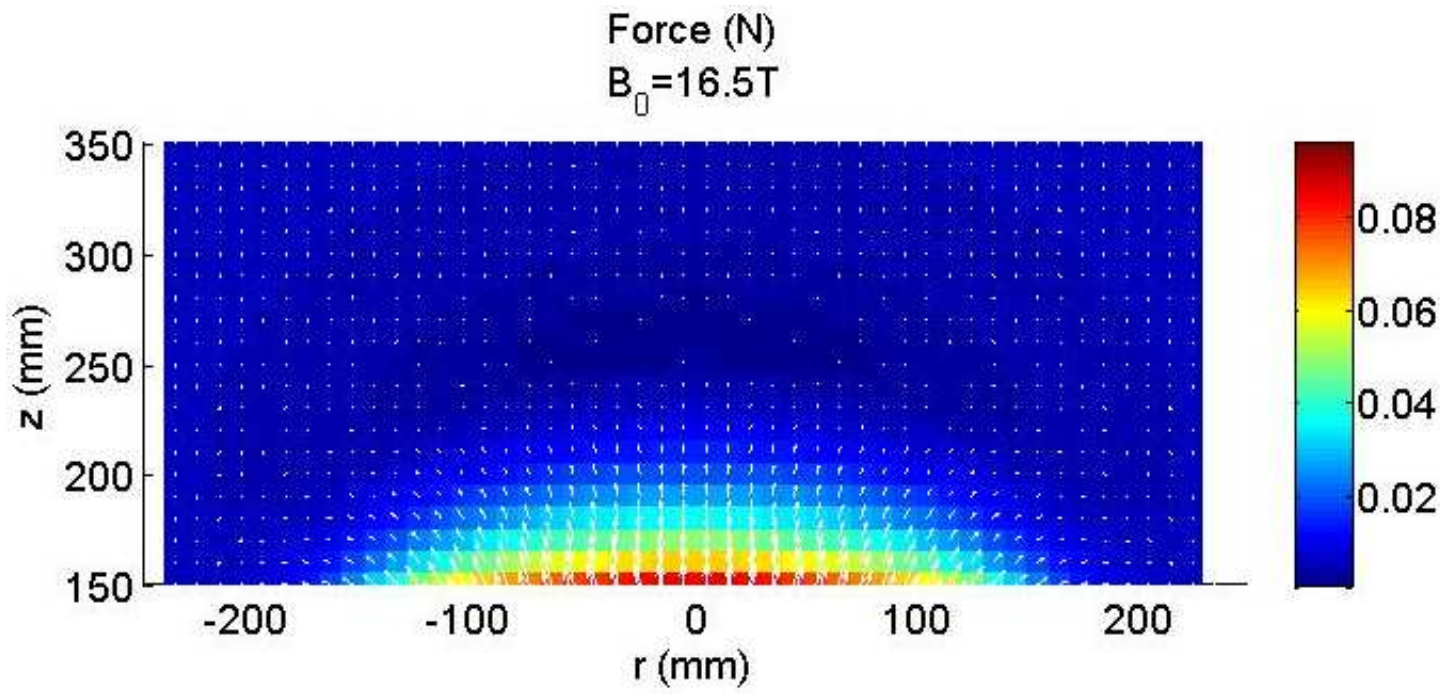

Fig. 6 Forces acted on glass particle $(d=1 \mathrm{~mm})$ in magnetic field $\left(B_{c}=16.5 \mathrm{~T}\right)$

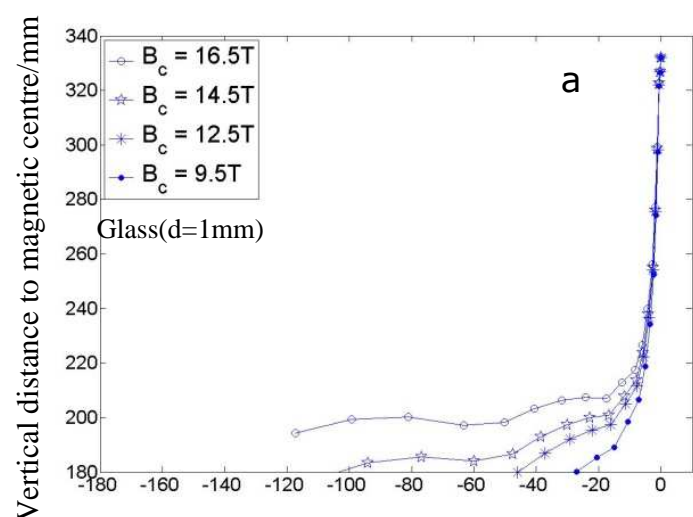

Radial distance to the magnetic centre/mm

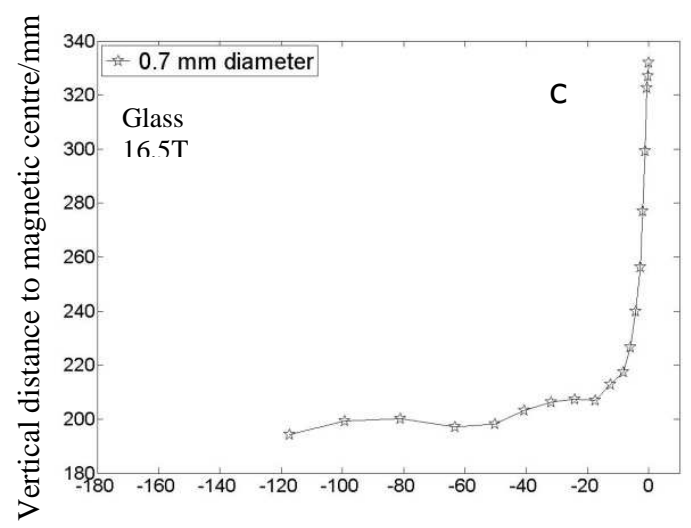

Radial distance to the magnetic centre/mm

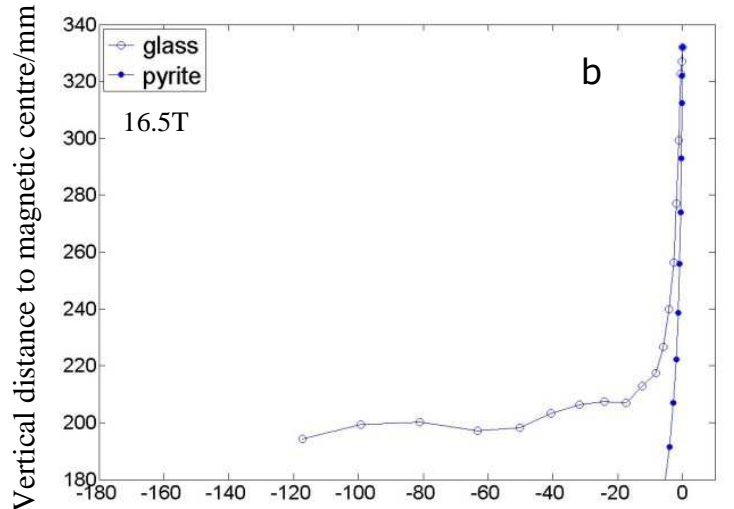

Radial distance to the magnetic centre/mm

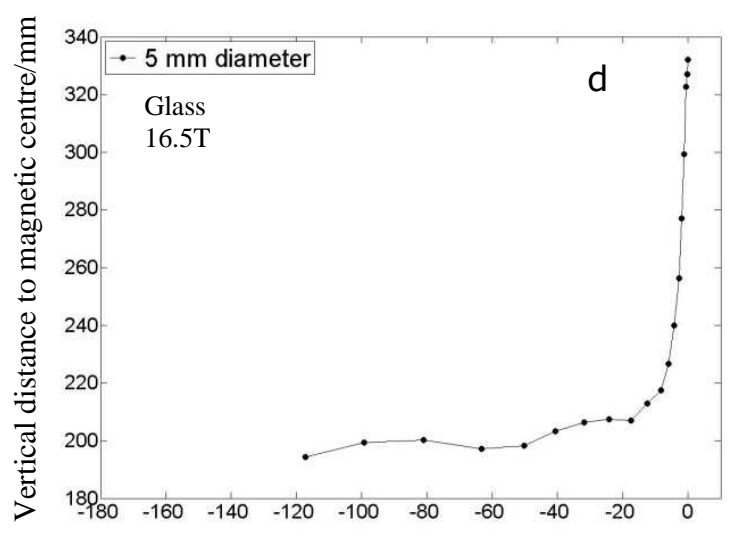

Radial distance to the magnetic centre/mm

Fig. 7 Simulation results of particle deflection in magnetic field 


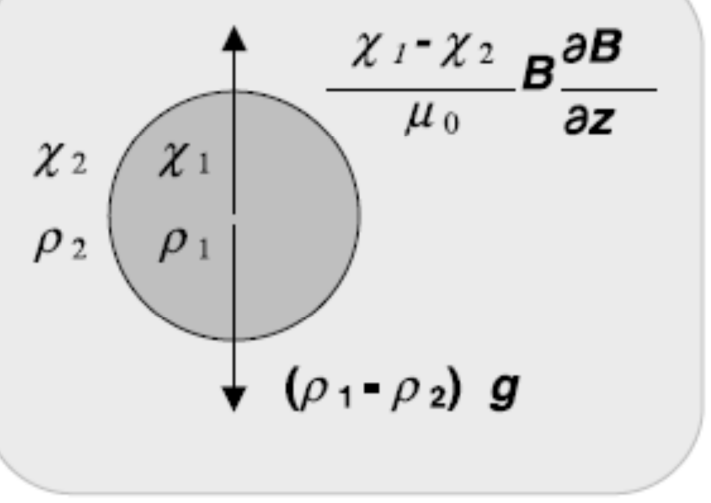

a. Forces balance(in the centre )

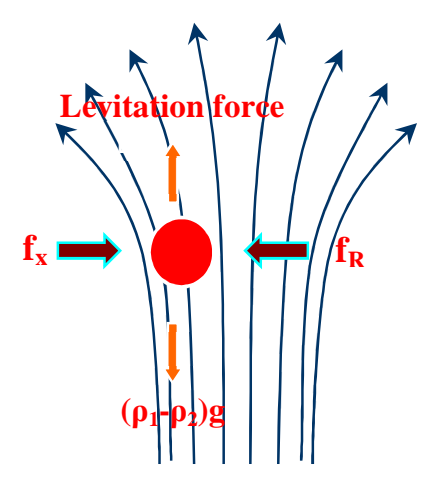

b. Forces balance(deviate from the centre)

Fig. 8 Forces acted on particles in magnetic field 